\title{
Imagens e Identidades da Docência: ser, tornar-se e fazer-se professor, professora
}

\author{
Vanessa T. Bueno Campos $^{1}$ \\ Maria de Lourdes Ribeiro Gaspar ${ }^{2}$ \\ Sarah Juvencino de Oliveira Morais ${ }^{3}$
}

\begin{abstract}
RESUMO
A identidade profissional docente não é inerente ou fixa; é complexa e construída a partir da significação social que atribuímos ao tornar-se e o fazer-se professor, professora. Essa premissa nos orientou, nesse artigo, tecermos reflexões sobre os conceitos em torno da constituição da identidade profissional docente decorrentes da produção de desenhos elaborados por estudantes da educação básica e superior. O questionamento que nos orientou foi: quais imagens são comumente relacionadas a docência e como é constituída a identidade profissional dos/as professores/as na percepção de estudantes? Optamos pela pesquisa exploratória com abordagem qualitativa, tendo como parâmetro no plano teórico e empírico, a revisão bibliográfica e a análise de conteúdo dos discursos expresso nos desenhos. A análise das produções dos discentes revelaram que a identidade profissional docente é compreendida por eles/elas na relação que estabelecem em sala de aula, marcada pela afetividade, pelo acesso ao conhecimento, pelas tradições sociais e culturais.
\end{abstract}

PALAVRAS-CHAVE: Identidade Docente. Formação Docente. Desenvolvimento Professional Docente.

\footnotetext{
1 Pós-Doutorado em Educação pela Universidade de São Paulo, São Paulo, SP, Brasil. Professora associada da Faculdade de Educação e Programa de Pós-Graduação da Universidade Federal de Uberlândia. https://orcid.org/0000-0002-5542-0980.vbcampos@ufu.br.

2 Doutora em Educação pela Universidade Federal de Minas Gerais, Belo Horizonte, MG, Brasil. Professora do Instituto Federal de Educação, Ciência e Tecnologia do Triângulo Mineiro - Campus Uberlândia Centro. https://orcid.org/0000-0002-1847-1148.marialourdes@iftm.edu.br.

${ }^{3}$ Mestranda em Educação pela Universidade Federal de Uberlândia, Uberlândia, MG, Brasil. https://orcid.org/00000001-8220-3335. sarahjoliveira@hotmail.com.
} 
Images and Identities of Teaching: to be, to become and to make yourself a teacher

\begin{abstract}
The professional identity of teachers is not inherent or fixed; it is complex and built from the social meaning we attribute to becoming a teacher. This premise guided us, in this article, to reflect on the concepts around the constitution of the teaching professional identity, resulting from the production of drawings prepared by elementary and high school students. The question that guided us was: which images are commonly related to the teaching work and how is the teachers 'professional identity constituted in the students' perception? We opted for exploratory research, with a qualitative approach, taking as a theoretical-empirical parameter, the bibliographic review and content analysis of the speeches expressed in the drawings prepared by the students. The analysis of the students 'productions revealed that the teachers' professional identity is understood by them in the relationship they establish in the classroom, marked by affection, access to knowledge, social and cultural traditions.
\end{abstract}

KEYWORDS: Teaching Identity. Teacher Education. Teacher Professional Development.

\author{
$* * *$ \\ Sim, sou eu, eu mesmo, tal qual resultei de tudo \\ Quanto fui, quanto não fui, tudo isso sou \\ Quanto quis, quanto não quis, tudo isso me forma... \\ (Álvaro de Campos, 1993, p. 114).
}

\title{
Introdução
}

Inspiradas pelas poéticas palavras de Álvaro de Campos ${ }^{4}$, compartilhamos, nesse artigo, as nossas reflexões sobre o processo tornar-se professor, professora, o qual supõe a troca de experiências, interações sociais, e a aprendizagem permanente.

\footnotetext{
${ }^{4}$ Heteronômio de Fernando Pessoa.
} 
A profissão docente, entre outras, é talvez aquela em que a natureza da identidade profissional mais sobressai pela complexidade, mutabilidade e plurivalência. Equacionada em convergência e interação com a formação, a identidade profissional emerge como movimento, cuja centralidade se espelha em aparente antinomia de permanência e mudança. (CAMPOS, 2017).

O ser humano nasce inacabado, é um projeto, um vir a ser. Ele tende à educação e o processo educativo pode ser entendido como uma condição para a sua humanização. A concepção do homem na perspectiva do devir, exige uma educação enquanto uma prática construtora do humano:

É na inconclusão do ser, que se sabe como tal, que se funda a educação como processo permanente; o fato de me perceber no mundo, com o mundo e com os outros me põe numa posição em face do mundo que não é de quem nada tem a ver com ele. Afinal, minha presença no mundo não é a de quem a ele se adapta, mas a de quem nele se insere. É a posição de quem luta para não ser apenas objeto, mas sujeito também da História. (FREIRE, 1996, p. 57)

Os seres humanos, se conscientes de seu "inacabamento", são seres da práxis - ação compreendida como um fazer permeado pela reflexão crítica que nos move no e com o mundo. O papel da educação está em colocar o ser humano como o centro deste processo transformador que visa concretizar um projeto educacional e tem como objetivo principal a formação permanente de diferentes sujeitos.

A formação de uma pessoa, conforme propõe Zabalza (2004), abrange o desenvolvimento pessoal do ser em seus singulares e complexos aspectos, desde conhecimentos e habilidades até seus valores e significados. $\mathrm{O}$ autor analisa que a formação está estreitamente relacionada à sua realização pessoal e profissional, indo muito além da experiencia escolar na educação básica e superior e dos conteúdos que fizeram parte da sua formação. Tal 
premissa nos possibilita compreender que a formação docente está em constante processo de desenvolvimento e, por conseguinte, a identidade docente a acompanha, a medida que as diversas fases do trabalho mudam, desde o ingresso na formação inicial, no início da carreira docente ao desenvolvimento docente ao longo da vida profissional.

Pesquisas em âmbito internacional e nacional têm confirmado não ser possível alcançar as mudanças na educação ignorando quem são os/as professores/as, o que eles/elas pensam e realizam. Diversos/as estudiosos/as como Arroyo (2000), Campos (2017), Campos e Almeida (2019), Campos e Silva (2019), Dubar (2005), Imbernón (2006), Melo e Campos (2019), Nóvoa (1992), Pimenta (2008), Tardif (2002) entre outros/as autores/as têm se preocupado com o trabalho docente e com a imagem social dos/as professores/as e ressaltam que a formação acontece permanentemente durante a trajetória de suas vidas.

Atualmente, vivemos em um momento histórico de profundas transformações. A situação atual dos/as professores/as pode ser analisada levando em conta as mudanças sociais que têm transformado (e por vezes transtornado) o seu trabalho e, a partir dessas céleres mudanças, é possível entendermos que a identidade docente não é estática, única, mas sim múltipla, dinâmica, em constante renovação.

A identidade profissional docente, de acordo com Nóvoa (1992, p. 16) não é um dado adquirido, uma propriedade ou um produto. Para o autor, "a identidade é um lugar de lutas e de conflitos, é um espaço de construção de maneiras de ser e de estar na profissão", por isso, a forma adequada de referir-se a ela é como "processo identitário, realçando a mescla dinâmica que caracteriza a maneira como cada um se sente e se diz professor" e completa, ainda, que:

A construção de identidades passa sempre por um processo complexo graças ao qual cada um se apropria do sentido da sua história pessoal e profissional. É um processo que necessita de 
tempo. Um tempo para refazer identidades, para acomodar inovações, para assimilar mudanças. (NÓVOA, 1992, p. 16).

A docência é marcada por relações sociais que interferem diretamente na construção da identidade profissional e os valores sociais mobilizados nessas relações agregam sentido e significado para a profissão docente e é preciso considerar que ao iniciar a carreira, os/as professores/as não chegam sozinhos/as na sala de aula, pois carregam consigo uma série de sentimentos, valores, crenças, saberes e ideais que foram construídos ao longo da sua trajetória pessoal, social e cultural.

Cunha (2004) aponta que futuros/as professores/as já possuem os marcos conceituais da profissão quando a elegem. Sendo assim, a dimensão humana não pode ser separada dos/as professores/as, porquanto são indissociáveis; sendo assim, dificilmente estes aspectos não intervirão nas suas práticas pedagógicas.

As imagens que temos de professores/as, segundo Arroyo (2000), são construções sociais e culturais, influenciadas pelo contexto e pelo momento histórico em que são elaboradas. Assim, em uma mesma localidade, é possível conviver com diferentes concepções de professor/a, de ensino e de escola.

A identidade profissional docente perpassa diversas questões que vão desde a sua socialização inicial, enquanto ainda estudante na educação básica, seguindo para a formação inicial em cursos de licenciatura, até tornar-se professor/professora de fato, ficando em formação permanente.

O desenvolvimento profissional docente é entendido por Marcelo Garcia (1992) como um processo contínuo que abarca diferentes etapas da vida profissional do/a docente.

Nessa perspectiva, apresentamos nesse artigo reflexões sobre a percepção de estudantes da educação básica e superior sobre a constituição da identidade docente a partir das imagens por eles/elas construídas no processo formativo. Para o desenvolvimento deste estudo, optamos por 
abordagem qualitativa, tendo como parâmetro no plano teórico, a revisão bibliográfica sobre a construção da(s) identidade(s) docente e no plano empírico, analisamos o conteúdo dos discursos de estudantes da educação básica e superior, expressos em desenhos.

As nossas interpretações, a partir dos desenhos dos/das estudantes, ressaltaram que as identidades docentes são constituídas a partir da significação social da profissão representadas por elementos como: professores/as marcantes, as tradições sociais e as contradições próprias da profissão.

\section{Ser e tornar-se professor, professora}

A nossa condição humana demanda o convívio social. Ao viver em sociedade passamos a representar diversos papéis que são permanentemente (re)construídos ao longo da nossa trajetória. Um dos papéis de maior representação para o ser humano é o seu papel profissional.

Nossas histórias influenciam nossos pensamentos, nossas concepções e construções de conceitos, afinal, "é impossível separar o eu profissional do eu pessoal". (NÓVOA, 1992, p. 17).

O professor, a professora não podem se despir da sua pessoa ao entrarem no onde trabalham e levam consigo as crenças, as alegrias, as decepções, as angústias os conflitos pessoais e profissionais. O autor sustenta que a forma como o/a docente ensina está diretamente relacionada com a representação que ele/ela tem de si mesmo ao ensinar.

Por meio de nossa atuação profissional nos formamos permanentemente junto com os nossos pares, porquanto, não é possível se referir a sociedade sem considerar o intenso movimento de (trans)formação que ela exerce em nós. Neste sentido a ação docente também está intrinsicamente relacionada aos processos de transformações que a sociedade vive cotidianamente. 
Corroborando com essa asserção, Marques (2006, p. 43) afirma que "o homem é, por natureza, o que é ou deseja ser; por isso necessita, ele mesmo, formar-se, segundo as exigências do seu ser e do seu tempo".

Dubar (2005) defende a existência de modos de identificação que corroboram com a construção e reconstrução contínuas da identidade de um sujeito. O autor ressalta a importância da identidade profissional para a construção da identidade individual, porquanto ela transita entre o indivíduo e o meio social no qual ele está inserido. Assim, cabe questionarmos: qual é ou quais são os modos de identificação que o sujeito pode ter com a docência?

O exercício da docência exige um movimento constante de (re)construção e de (re)interpretação da prática e do contexto escolar; exige responsabilidade e consciência da importância do/a professor/a na constituição da sociedade e nos valores nela imputados.

A educação é uma prática social em meio a um processo de socialização que resulta conquistas sociais e produção do conhecimento. A prática educativa acontece em diversos espaços na vida social, sendo praticada por diversas pessoas, não apenas professores/as, pois é através da mediação do mundo que os homens e mulheres se educam mutualmente na direção de compreender, criticar e se posicionarem diante da realidade que os cerca. (FREIRE, 1996).

Frente ao exposto, um dos desafios postos pela humana e complexa docência é a promoção de uma formação permanente que viabilize momentos destinados à reflexão pessoal e coletiva capazes de promover o desenvolvimento profissional permanente e compartilhado.

\section{A construção da identidade docente exige formação permanente}

Os seres humanos constroem e reconstroem a sua identidade mediante as relações sociais estabelecidas com seus pares. A nossa 
identidade não é imutável, não é um dado inerte e consolidado, e por isso mesmo exige dos seres humanos um exercício permanente de reflexão sobre o seu papel no mundo e com o mundo. Savater $(1996$, p.26) assevera que nós, os seres humanos, "somos animais sociais, mas não somos sociais no mesmo sentido que o resto dos animais".

A sociedade humana, organizada com base no trabalho humano, ultrapassa a natureza, tem uma dimensão histórica e cultural e rompe com o determinismo, movimenta-se, transforma-se permanentemente:

A educação é permanente não por que certa linha ideológica ou certa posição política ou certo interesse econômico o exijam. A educação é permanente na razão, de um lado, da finitude do ser humano, de outro, da consciência que ele tem de finitude. Mas ainda, pelo fato de, ao longo da história, ter incorporado à sua natureza não apenas saber que vivia mas saber que sabia e, assim, saber que podia saber mais. A educação e a formação permanente se fundam aí. (FREIRE, 1993, p. 22-23).

A identidade é algo construído nos limites da existência social dos sujeitos e cada um compõe a sua identidade na relação com os outros, no reconhecimento de sua presença no mundo.

A identidade é constituída por processos contínuos, históricos, sociais e, por conseguinte, as interações com as outras pessoas são requisitos para o desenvolvimento humano. Além disso, nossa identidade é relacionada com as narrativas que os outros fazem de si para si e para os outros (GENTIL, 2006).

A identidade profissional é um dos aspectos que compõe as várias identidades que cada um de nós carrega. A identidade profissional é dinâmica, pode ser estudada em função de suas características e se desenvolve continuamente em detrimento de cada história de vida; ela é permanentemente construída por meio de nossas escolhas, que podem se 
conscientes ou não, com significados ou orientações distintas (DUBAR, 2005).

A identidade profissional docente é formada a partir de nossas interações sociais, mediada pela conscientização do papel profissional que escolhemos e exercermos. Essa relação envolve aspectos relacionais e individuais além do significado que cada um atribui a profissão.

Nessa perspectiva, consideramos oportuna a proposição de Freire (1995, p. 58) sobre a necessidade da formação profissional para o exercício do magistério, quer seja na educação básica ou superior, pois : "Ninguém começa a ser educador numa certa terça-feira às quatro horas da tarde, ninguém nasce educador ou marcado para ser educador", porque a docência saberes específicos para o seu exercício.

No entanto, é necessário compreendermos que identidade docente não é construída pelo número de cursos ou técnicas acumuladas, mas sim através de um trabalho contínuo sobre si mesmo orientado pela reflexão crítica sobre a própria prática e da (re)construção permanente da identidade pessoal.

A formação docente permanente, afirma Imbernón (2006), não deve ser interpretada como uma mera atualização científica, pedagógica ou cultural. Ela deve priorizar a descoberta da teoria para uma organização, fundamentação e revisão das práticas pedagógicas, transformando o seu sentido comum por meio da promoção da unidade teoria-prática para sustentar o fazer docente.

A formação docente, nesse sentido, deve estar alinhada a uma perspectiva de desenvolvimento profissional que tem, na formação inicial, o começo de um processo contínuo no qual a profissão se desenvolve por meio de descobertas individuais e coletivas que se sedimentam e se (re)constroem por meio de uma rigorosa reflexão crítica sobre a prática mediada pela teoria, o que permite a reconstrução da experiência na perspectiva do aprimoramento da atuação docente. (ALMEIDA, 2006). 
A qualidade do ensino exige formação permanente do professorado, uma vez que o conhecimento restrito da sua área de formação não é suficiente para enfrentar as dificuldades e as exigências atuais. Logo, a qualidade da educação requer o compromisso com o desenvolvimento

profissional docente. É preciso empenho para estimular a criação e a manutenção de espaços coletivos para discussão da prática pedagógica docente.

A formação permanente dos professores é um princípio elementar para qualificar e alcançar êxito no processo de ensino-aprendizagem, pois estimula os docentes a (re)pensarem suas práticas e a modificarem crenças que porventura impeçam a adoção de novos métodos de ensino.

\section{As imagens da docência e a docência nas imagens}

O Grupo de Estudos e Pesquisas em Docência na Educação Básica e Superior - GEPDEBS, vinculado a Linha de Pesquisas Saberes e Práticas Educativas, do Programa de Pós-Graduação em Educação, da Universidade Federal de Uberlândia - MG, desenvolve ações de formação em encontros quinzenais, promovendo discussões e reflexões críticas relativas ao desenvolvimento profissional docente, a formação inicial, contínua, saberes, práticas, identidade docente, entre outras temáticas. O grupo realiza seminários com a colaboração de seus/suas integrantes e estende a participação aos professores e professoras de escolas da rede pública e particular de Uberlândia e região, objetivando promover o desenvolvimento profissional docente.

Nesse cenário, realizamos em 2019, um seminário sobre a temática Identidade Profissional Docente, com o intuito de promovermos reflexões sobre a constituição da identidade docente a partir da construção das imagens da profissão docente elaboradas por estudantes da educação básica e superior. 
Para tanto, propusemos aos/às discentes que elaborassem desenhos para que pudessem expressar os sentidos e significados que atribuem à profissão docente. Colaboram 18 estudantes de um curso de licenciatura de uma IES pública e 30 estudantes da educação básica de nível médio de uma Instituição Federal e 23 estudantes da educação básica do ensino fundamental de escola da rede municipal ${ }^{5}$, instigados a desenharem a partir da pergunta: "O que é ser professor, professora para você?"

As interpretações apresentadas por meio da técnica Análise de Conteúdo, de Bardin (1977), nos permitiu afirmar que as imagens e a identidade profissional dos docentes constroem-se com base na significação social da profissão, de suas tradições e no fluxo histórico de suas contradições.

Nessa perspectiva, é necessário considerarmos que uma mesma imagem pode apresentar diferentes (re)significações, variando conforme as explanações e usos que são feitos delas.

A imagem, assim como algumas palavras, pode ser polissêmica. O desenho é uma imagem não verbal. Como exemplos de linguagem nãoverbal, traduzem uma visão de mundo porque traduzem pensamentos, revelam conceitos.

Logo, ler um desenho e analisar o seu conteúdo não é tarefa simples, implica em compreender como seu autor leu o mundo a partir de suas experiencias. O papel do/a pesquisador/a é ler, reler, analisar e interpretar o ponto de vista de seu/sua autor/a:

Ler significa reler e compreender, interpretar. Cada um lê com os olhos que tem. E interpreta a partir de onde os pés pisam. Todo ponto de vista é a vista de um ponto. Para entender como alguém lê, é necessário saber como são seus olhos e qual é sua visão de mundo. Isso faz da leitura sempre uma releitura. A cabeça pensa a partir de onde os pés pisam. Para compreender, é essencial

\footnotetext{
${ }^{5}$ Salientamos que, do conjunto de 71 desenhos, selecionamos cinco para compor esse artigo, sendo dois são de estudantes de curso de licenciatura, dois do ensino médio e um da educação básica.
} 
conhecer o lugar social de quem olha. Vale dizer: como alguém vive, com quem convive, que experiências tem, em que trabalha, que desejos alimenta, como assume os dramas da vida e da morte e que esperanças o animam. Isso faz da compreensão sempre uma interpretação. Sendo assim, fica evidente que cada leitor é coautor. Porque cada um lê e relê com os olhos que tem. Porque compreende e interpreta a partir do mundo em que habita. (BOFF, 2010, p. 9).

O desenho, por se constituir em uma forma de linguagem não verbal, traduz uma imagem, construída em um determinado contexto histórico, social e cultural e tem papel importante tanto no desenvolvimento da capacidade cognitiva e semiótica, como também na criatividade e expressão das emoções.

Considerando o desenhar como uma atividade criadora, podemos pensar que ela expressa os sentimentos de seu/sua autor/a e o modo como a realidade é por este apropriada e transformada.

Ao desenharmos, expressamos o nosso entendimento sobre o mundo, sobre a imagem apreendida em nossas relações com o mundo. Essa acepção se traduziu no desenho (Figura 1) realizado por um/a estudante do ensino fundamental I de uma escola pública no município de Uberlândia - MG, sobre o que é ser professor, professora. 
Figura 1: O que é ser professor/professora?

Fonte: Desenho do/a Estudante 1 - Ensino Fundamental I

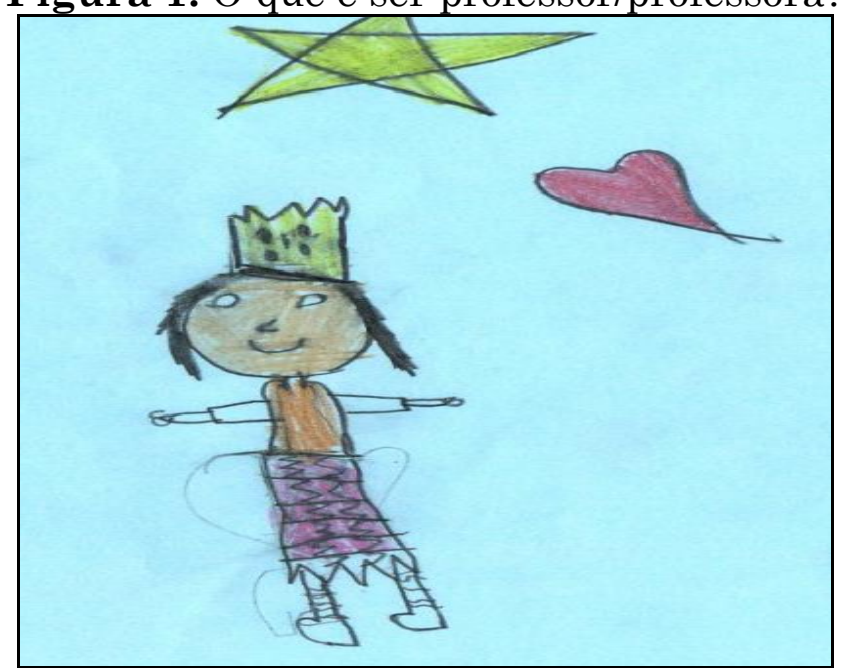

A imagem em destaque representa uma perspectiva romantizada e virtuosa da profissão docente, perceptível nas cores vibrantes utilizadas para colorir o desenho, no coração e na estrela e pela postura corporal da professora que, de braços abertos, sugere um afetuoso abraço. Além disso a professora traz uma coroa na cabeça que nos remete ao universo dos contos de fadas, no qual a rainha ou a princesa é a pessoa mais importante e o centro das relações.

A partir da análise do conteúdo, a criança expressa, nas entrelinhas de seu desenho, a crença de que a professora exerce a docência por amor, porque gosta. Campos e Silva (2019, p. 255), salientam que em geral os/as estudantes entendem a docência a partir de "um ideário difícil de ser superado: a compreensão do magistério como vocação ou dom, a imagem de perfeição dos professores como sujeitos que tudo sabem".

Ao longo da história, a profissão docente tem oscilado de acordo com os interesses da sociedade vigente. Desde a chegada dos primeiros jesuítas ao Brasil, ainda no século XVI, até início do século XX, a docência era associada ao sacerdócio, a vocação, missão e/ou um dom, pois acreditava-se que a pessoa nascia para ser professor/a. Esse perfil de professor/a como missionário/a, vocacionado/a, que nasceu para a docência, ainda hoje, 
primeira década do século XXI, influencia e, por que não dizer, dificulta a consolidação da docência como profissão.

As três concepções - vocação, ofício e profissão - exprimem uma linha de evolução do ensino, que, com maior ou menor grau, estão presentes na contemporaneidade; representam dilemas que envolvem a profissão docente e geram contradições e antagonismos no que se refere à formação que o/a professor/a deve ter, quais são os saberes, os conhecimentos necessários para o exercício da profissão.

As práticas docentes são constituídas por um conjunto de valores, princípios, conhecimentos e atitudes histórica e socialmente situadas, incluindo a trajetória pessoal dos/as professores/as, experiências construídas, espaço e contexto em que atuam.

Estudos sobre a constituição epistemológica, pedagógica e histórica da docência evidenciam que a atividade ainda carece de muitos elementos para se tornar reconhecida como um campo constituído por saberes próprios legitimados e respeitados. Para Nóvoa (2008), ainda há a tendência de se considerar que basta dominar bem o conteúdo de ensino e ter certa aptidão de comunicação para ser professor/a, o que leva à perda de prestígio da profissão e à ausência de um status de cientificidade.

Ser e tornar-se docente requer formação longa e contínua, fundamentada na autonomia do fazer pedagógico, enfrentando problemas decorrentes da realidade profissional na tomada de decisões e na superação deles. A formação permanente deve fomentar a aquisição de conhecimentos pedagógicos para subsidiar a intervenção docente no processo ensinoaprendizagem.

Nessa perspectiva, na Figura 2, analisamos um desenho produzido por um estudante do ensino médio que nos remete a reflexão sobre as diversas nuances da identidade docente no que diz respeito as suas características e atribuições. 
Figura 2: O que é ser professor/professora?

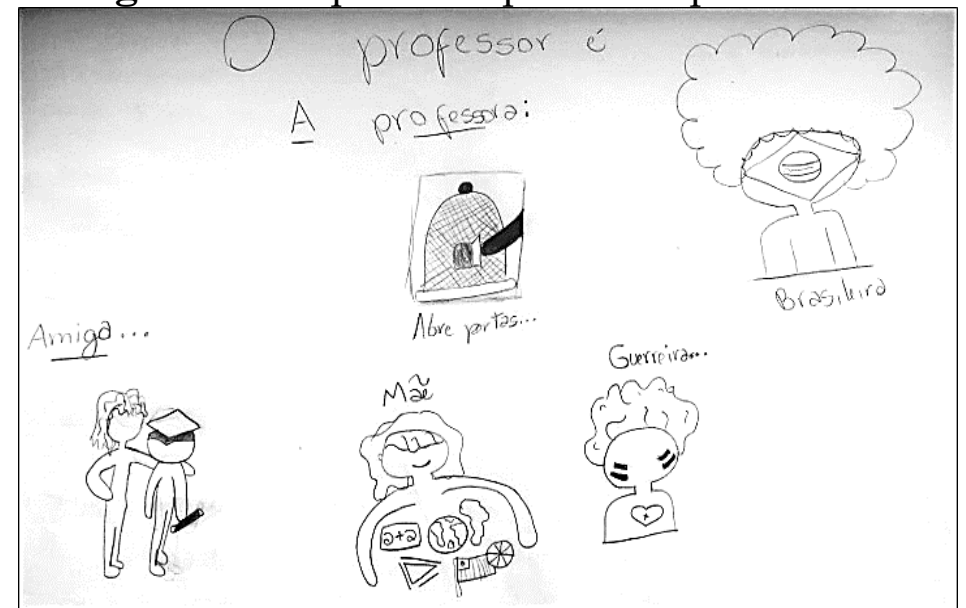

Fonte: Desenho do/a Estudante 2 - Ensino médio

No desenho o/a estudante apresentou a professora em diferentes papéis, evidenciando a sua compreensão sobre as diversas faces da docência, não só na dimensão profissional, mas também na sua condição de mulher, mãe, guerreira, amiga e traz estampada na roupa e no rosto a bandeira do Brasil, enfatizando a importância do seu papel na educação.

No desenho é perceptível a admiração do estudante pela profissão, visto que, além das qualidades que foram atribuídas a professora, na imagem central observamos uma porta que conduz os/as estudantes ao conhecimento, a pensarem criticamente e alargarem sua visão de mundo.

$\mathrm{Na}$ opinião de Rios (2018, p. 24), o mundo é do tamanho "do conhecimento que temos dele. Alargar o conhecimento, para fazer o mundo crescer, e apurar seu sabor, é tarefa do ser humano. É tarefa, por excelência, de educadores". Embora concordemos com a autora, consideramos também que a professora deveria ser identificada a partir de um processo permeado por histórias individuais e coletivas, por conceitos familiares, sociais, culturais, reais e não ideais.

A docência é uma atividade plural e repleta de dilemas pelo fato de ser uma profissão essencialmente humana, ou seja, se sustenta por meio de relações e interações com e entre seres humanos. São inúmeras pessoas com as quais o/a professor/a tem de lidar, em um mesmo espaço e, em geral, por 
tempo considerável, administrando tensões, resistências, atitudes diversas e, em alguns casos, até reações adversas.

Apreender e incorporar o real e ao processo formativo, nos impasses e contradições das práticas educativas pode ser desestabilizador, contudo nos permite criar um espaço de aprendizagem, pois nem sempre o que o outro é nos agrada, porém poderá nos instigar a mudança de atitudes, seja pela identificação, seja pela diferenciação. E as provocações nos movimentam em outras direções que se definem como possibilidades à medida que são identificadas, discutidas, confrontadas, compartilhadas. Esse processo amadurece a escolha.

O confronto, nessa perspectiva, é inevitável e parte inerente desse processo e, quando explicitado, favorece uma releitura dos conhecimentos/saberes e dos valores em que eles se apoiam e corpereificam, como podemos observar no desenho elaborado por um estudante do ensino médio.

Figura 3: O que é ser professor/professora?

Fonte: Desenho do/a Estudante 4 - Ensino Médio
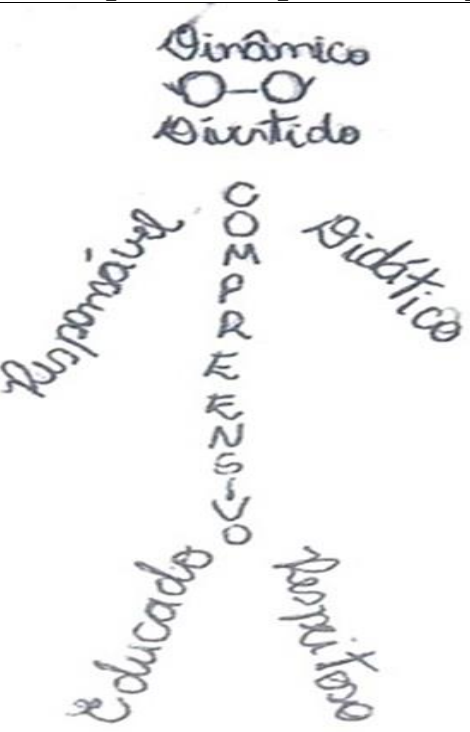

$\mathrm{Na}$ Figura 3 o "corpo docente" foi formado por palavras que exemplificam as características que o aluno considera como essenciais para 
o perfil docente: dinâmico, divertido, responsável, compreensivo, didático, educado, respeitoso. Reconhecemos na singular e sugestiva imagem, construída pelo/a discente, um/a professor/a humanista.

O humanismo na identidade docente demanda assunção e exercício permanente das qualidades indispensáveis à ação docente, as quais devem ser construídas e exercidas na prática docente, cuja intencionalidade política-pedagógica é democrática e progressista:

[...] É preciso que saibamos que, sem certas qualidades ou virtudes como amorosidade, respeito aos outros, tolerância, humildade, gosto pela alegria, gosto pela vida, abertura ao novo, disponibilidade à mudança, persistência na luta, recusa aos fatalismos, identificação com a esperança, abertura à justiça, não é possível a prática pedagógico-progressista, que não se faz apenas com ciência e técnica (FREIRE, 1996, p. 120).

$\mathrm{Na}$ docência progressista e democrática, a ciência e a técnica devem sustentar-se em atitudes humanas: amorosidade, ética, compromisso, em uma relação dialógica, horizontal, entre educando e educador constituindose em um ato político. Essa educação não pode ser neutra, porque não é possível separar educação e política.

Não podemos praticar uma educação voltada para a cidadania sem nos envolver afetivamente e sem agregarmos a ela nossa intencionalidade política, pois de acordo com Freire (1996, p. 143): “A prática educativa é tudo isso: afetividade, alegria, capacidade científica, domínio técnico a serviço da mudança”, consequentemente, a formação da identidade docente progressista requer a assunção de um estado democrático de ser e atuar.

A formação do/a professor/a democrático/a, mesmo em um regime autoritário, como a atualidade brasileira se apresenta, não pode deixar de se fixar no campo da problematização da realidade, utilizando como principal 
instrumento a interação libertadora entre docente-estudante, conhecimentoensino-aprendizagem.

A formação nesse sentido é inesgotável, incompleta, inacabada, construída a partir das múltiplas relações entre as pessoas envolvidas, docentes, estudantes, comunidade escolar entre os seus saberes, valores, desejos, sentimentos, entre o que é vivenciado, modificado, apropriado, recriado, criado.

Entretanto, não podemos esquecer que em meio as exigências sociais, de caráter amplo, há um conjunto de condicionantes específicos dos lugares nos quais os docentes atuam, caracterizados por aspectos estruturais, administrativos e pedagógicos, somados às variáveis do espaço em que ocorre efetivamente a docência, acrescendo-se as características socioculturais e as expectativas do grupo de estudantes.

Assim, ser e tornar-se docente é também lidar com um conjunto de variáveis presentes no cotidiano, desde o planejamento, elaborado na expectativa da participação de um determinado grupo de pessoas, cuja reação pode ser diferente da esperada aos aspectos que envolvem a instituição escolar, até as relações profissionais e com a comunidade escolar, os materiais e recursos disponíveis ou não, a organização curricular, as demandas específicas da turma e da escola.

Dessa forma, entendemos que a docência não é uma tarefa simples, meramente repetitiva, mas exige criatividade, constante atenção e formação contínua. Tal premissa pode ser identificada na Figura 5, na qual uma licencianda expos a sua compreensão sobre a ação docente em duas tendências: liberal e progressista. 
Figura 4: O que é ser professor/professora

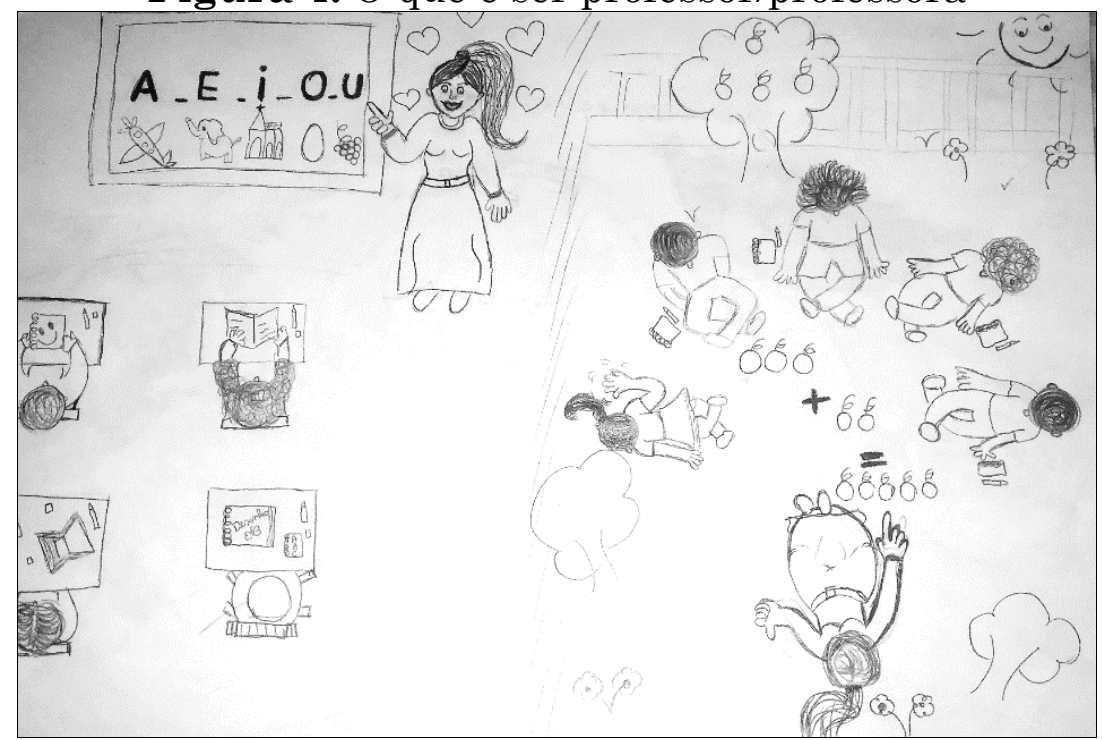

Fonte: Desenho do/a Estudante 5 - Curso Licenciatura

A análise da parte esquerda do desenho nos remete a uma imagem mais conservadora da docência. Tal assertiva é possível ao observarmos a disposição dos/as alunos/as na sala, sentados em fileiras com livros abertos e olhando para frente. No centro da sala, encontra-se a professora ensinando de forma expositiva com conteúdo no quadro. Além disso, a postura (saia longa e os cabelos presos) é professoral. Em torno da professora, observamos corações que demonstram novamente a visão romantizada da docência ou da professora como tia.

$\mathrm{Na}$ Figura 4, do lado direito, a aula foi representada em um ambiente diferenciado. Aparentemente os/as estudantes e a professora encontram-se em um ambiente externo e observamos o registro de imagens relativas a natureza e também pelo fato de estarem sentados em roda, no chão e constroem o conhecimento matemático utilizando frutas na árvore que está disposta no fundo do desenho e que provavelmente foram colhidas antes do início da aula. No entanto, a professora permanece com a mesma vestimenta do desenho anterior e está ocupando o lugar no centro da roda.

Deduzimos que, sendo o desenho de autoria de uma estudante do curso de licenciatura, a futura docente, implicitamente, apresentou a sua compreensão sobre uma nova forma de significação social da profissão, 
demonstrando que os saberes construídos no espaço de formação inicial podem contribuir para modificar a maneira como o/a professor/a se reconhece; recorremos a Marcelo Garcia (2009, p. 112) para apreendermos a percepção da estudante sobre a identidade profissional, enquanto um:

[...] processo evolutivo de interpretação e reinterpretação de experiências, uma noção que coincide com a ideia de que o desenvolvimento dos professores nunca para e é visto como uma aprendizagem ao longo da vida. Desse ponto de vista, a formação da identidade profissional não é a resposta à pergunta "quem sou eu neste momento?", mas sim a resposta à pergunta "o que quero vir a ser?

Os processos de formação são complexos e nos desafiam a percorrer outros caminhos e possibilidades que considerem as diferentes dimensões afetivas, epistemológicas, cognitivas, técnicas, éticas, estéticas, políticas, sociais, porque ampliam a ação docente, ao mesmo tempo em que nos exigem estabelecer, continuamente, relações entre: a prática pedagógica e os seus múltiplos saberes e fazeres, compreendidos como prática social.

Os espaços da formação docente são múltiplos assim como os saberes existentes em nosso vasto e complexo mundo. Esses saberes compõem uma tessitura singular e ao mesmo tempo complexa, que se constitui e se expressa no que somos e no que fazemos, perpassando tanto nossas identidades, como as práticas com as quais estamos envolvidos.

Os horizontes dos processos de formação estão intimamente relacionados aos modos de se perceber a educação e as diferentes formas de aprender. Na Figura 5 o desenho de estudante de licenciatura nos convida a abrir janelas. 
Figura 5: O que é ser professor/professora?

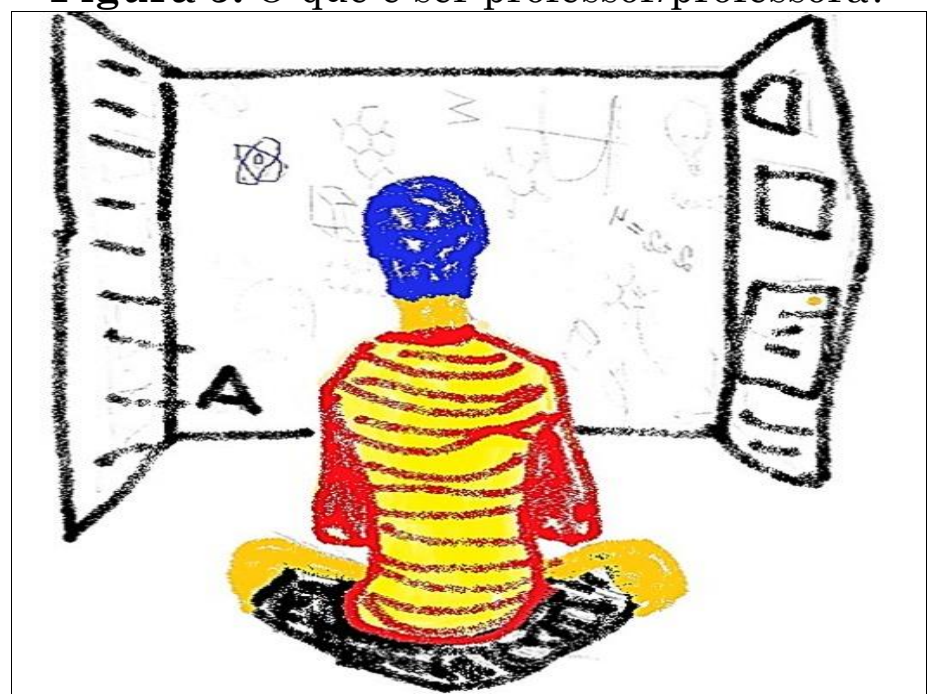

Fonte: Desenho do/a estudante 6 - Curso de Licenciatura.

A imagem faz alusão, em um primeiro olhar, a um/a professor/a sentado/a em frente lousa na sala de aula. Essa hipótese pode ser confirmada a partir da observação dos escritos na lousa, expondo os conteúdos trabalhados pelo/a docente. No entanto, se analisarmos mais atentamente, é possível enxergar não mais a lousa, mas uma janela. Essa análise nos permite compreender que os escritos não estão na lousa, mas fazem menção do olhar do/a docente para o horizonte, representando um pensamento, um momento de reflexão do/a professor/a sobre a sua prática pedagógica, a qual deverá promover a autonomia, provocar inquietudes, aguçar a curiosidade como nos ensinou Freire (1996, p. 53), pois "a leitura do mundo precede a leitura da palavra" e contribui para abrirmos janelas onde há somente muros e esperançar.

Sim, esperançar e não esperar, como nos ensinou o mestre Freire (1996). Esperançar exige compromisso, respeito, perseverança, disciplina, resistência e luta. Lutar mesmo diante das impossibilidades do atual cenário político brasileiro, marcado pelo desrespeito aos direitos humanos, que nos angustia e ao mesmo tempo nos exige esforços coletivos em prol de uma educação comprometida com a equidade, justiça e inclusão social, porque a nossa "presença no mundo não é a de quem nele se adapta, mas de quem 
nele se insere. É a posição de quem luta para não ser apenas objeto, mas sujeito também da história" (FREIRE, 2001, p. 57).

\section{Considerações finais}

Nesse artigo objetivamos analisar as diversas faces que constituem a identidade a docência e reafirmar a importância da implementação de espaços para formação permanente dos professores. Uma formação fundamentada em uma perspectiva do ser humano como um ser inconcluso, inacabado, em movimento permanente de busca. Nesta perspectiva, se deparam com uma busca incessante por conhecimentos e alternativas diversificadas para sua atuação profissional.

Não existe neutralidade na ação educativa: a educação é um ato político, social. As ações docentes são carregadas de representações que (re)configuram constantemente a sua identidade profissional. Como sujeitos inseridos no mundo, os/as docentes se (trans)formam, consciente ou inconscientemente, com as mudanças sociais e, por conseguinte, precisam refletir criticamente sobre suas práticas pedagógicas.

A partir das reflexões suscitadas com base nos desenhos produzidos por estudantes da educação básica e superior, depreendemos que o percurso formativo docente ocorre mesmo antes da sua atuação na sala de aula, pois os acontecimentos pretéritos influenciam diretamente na constituição de sua identidade pessoal e profissional.

Imersos/as em um contexto de intensas e rápidas transformações, os/as docentes necessitam de um espaço permanente para socializar seus saberes e práticas de forma crítica e reflexiva, que ofereça elementos teóricos, práticos e metodológicos para direcionar a sua prática pedagógica que promova a superação da dicotomia entre a teoria-prática.

Reiteramos a importância da criação e manutenção de espaços de formação permanente, para (re)pensarmos sobre o exercício da docência, 
seus desafios e possibilidades de emancipação. A formação docente, nessa perspectiva, deve ser orientada por princípios humanísticos, voltados para a reflexão crítica sobre a prática, a coletividade e os aspectos sociais que vigem na e para além da instituição e que afetam diretamente o fazer pedagógico dos/as docentes e a constituição da sua identidade profissional.

Esperançamos que as nossas reflexões contribuam para (re)significar a compreensão sobre a formação permanente, para que a constituição da identidade profissional docente tenha como marca indelével a humana docência.

\section{Referências}

ALMEIDA, Maria Isabel de. Apontamentos a respeito da formação de professores. In: BARBOSA, Raquel L. L. (Org.). Formação de educadores: artes e técnicas, ciências e políticas. São Paulo: UNERSP, 2006.

ALMEIDA, Maria Isabel de. Pedagogia universitária e projetos institucionais de formação e profissionalização de professores universitários. 2011.147 f. Tese (LivreDocência) - Faculdade de Educação, Universidade de São Paulo, São Paulo, 2011.

ARROYO, Miguel G. Ofício de Mestre: Imagens e Auto-Imagens. Petrópolis: Vozes, 2000.

BARDIN, Laurence. Análise de conteúdo. Lisboa: Edições 70, 1977.

BOFF, Leonardo. A águia e a galinha. Uma metáfora da condição humana. Rio de Janeiro: Vozes, 2010, p. 9

CAMPOS, Vanessa T. B. Ações formativas como estratégia de desenvolvimento profissional de professores na educação superior e (trans)formação da prática docente na Universidade Federal de Uberlândia - MG. Relatório Estágio PósDoutoral. Faculdade de Educação. Universidade de São Paulo. São Paulo. 2017.

CAMPOS, Vanessa T. Bueno; ALMEIDA, Maria Isabel de. Contribuições de ações de formação contínua para a (trans)formação de professores universitários. Revista Linhas. Florianópolis, v. 20, n. 43, p. 21-50, maio/ago. 2019.

CAMPOS, Vanessa T. B. \& SILVA, Fernanda D. A. (Trans)formação da docência: contribuições das experiências de vida à formação inicial de professores. ETD Educação Temática Digital, 21(1), 242-258. 2019. 
CUNHA, Maria Isabel da. A docência como ação complexa: o papel da Didática na formação de professores. In: ROMANOWSKI; José P. MARTINS, Pura L. O.; JUNQUEIRA, Sérgio R. Conhecimento local e conhecimento universal: pesquisa, didática e ação docente. Curitiba: Champagnat, 2004, p. 31-42.

DUBAR, Claude. A socialização: construção das identidades sociais e profissionais. Tradução: Andrea Stahel M. da Silva. 3. ed. São Paulo, SP: Martins Fontes, 2005.

FREIRE, Paulo. Política e educação. Indaiatuba: Villa das Letras Editora, 1993.

FREIRE, Paulo. Pedagogia da Autonomia: saberes necessários à prática educativa. 53. ed. São Paulo: Paz e Terra, 1996.

FREIRE, Paulo. A educação na cidade. 2. ed. São Paulo: Cortez, 1995.

FREIRE, Paulo. Educação e mudança. 24. ed. São Paulo: Paz e Terra, 2001.

GENTIL, Heloisa S. Identidades de professores e redes de significações configurações que constituem o "nós" professores. Revista Psicologia da Educação, São Paulo, 23, $2^{\circ}$ sem. de 2006, pp. 175-188.

IMBERNÓN, Francisco. Formação docente e profissional: formar-se para a mudança e a incerteza. 6. ed. São Paulo: Cortez, 2006.

MARCELO GARCIA, Carlos. Os professores e sua formação. In: NÓVOA, A. (org). Formação de professores e profissão docente. Lisboa: Dom Quixote, 1992.

MARCELO GARCIA, Carlos. A identidade docente: constantes e desafios. Formação Docente, Belo Horizonte, v. 01, n. 01, p. 109-131, ago./dez. 2009. Disponível em http://formacaodocente.autenticaeditora.com.br. Acesso em:12 maio 2019.

MARQUES, Mário O. A formação do profissional da educação. $5^{\mathrm{a}}$ Ed. Unijuí, 2006.

MELO, Geovana Ferreira; CAMPOS, Vanessa T. Bueno. Pedagogia universitária: por uma política institucional de desenvolvimento docente. Cadernos de Pesquisa, São Paulo, v. 49, n. $173, \quad$ p. $44-63$, jul./set. 2019. https://doi.org/10.1590/198053145897.

NÓVOA, António. Formação de professores e profissão docente. In: NÓVOA, A. (coord.). Os professores e a sua formação. Lisboa: Dom Quixote, 1992. p.15-33.

NÓVOA, António. Os professores e o "novo" espaço público da educação. In: TARDIF M. e LESSARD, C. (org.) $O$ ofício de professor: história, perspectivas e desafios internacionais. Petrópolis (RJ): Vozes, 2008, p. 217-233.

PESSOA, Fernando. Poesias de Álvaro de Campos. Lisboa: Ática, 1944.

PIMENTA, Selma G. Saberes pedagógicos e atividades docentes. 6. ed. São Paulo: Cortez, 2008. 
SAVATER, Fernando. Política para meu filho. S. Paulo, Martins Fontes, 1996.

RIOS, Terezinha Azeredo. Compreender e ensinar: por uma docência da melhor qualidade. São Paulo: Cortez, 2008.

TARDIF, Maurice. Saberes docentes e formação profissional. 3. ed. Petrópolis: Vozes, 2002.

ZABALZA, Miguel. O ensino universitário: seu cenário e seus protagonistas. Porto Alegre: Artmed, 2004.

Recebido em junho de 2019.

Aprovado em novembro de 2019. 